\title{
Adaptive Cutting Control for Roadheaders Based on Performance Optimization
}

\author{
Qingyun Liu, Chao Lu (D), Tao Liu * and Zhangbao Xu \\ School of Mechanical Engineering, Anhui University of Technology, Anhui 243000, China; \\ lqyahjx@ahut.edu.cn (Q.L.); chaoluab@163.com (C.L.); xuzhangbao1988@163.com (Z.X.) \\ * Correspondence: 1t_ahut@ahut.edu.cn
}

Citation: Liu, Q.; Lu, C.; Liu, T.; Xu, Z. Adaptive Cutting Control for Roadheaders Based on Performance Optimization. Machines 2021, 9, 46. https: / / doi.org/10.3390/ machines 9030046

Academic Editors: Mariusz Deja and Angelos P. Markopoulos

Received: 4 February 2021

Accepted: 21 February 2021

Published: 24 February 2021

Publisher's Note: MDPI stays neutral with regard to jurisdictional claims in published maps and institutional affiliations.

Copyright: (c) 2021 by the authors. Licensee MDPI, Basel, Switzerland. This article is an open access article distributed under the terms and conditions of the Creative Commons Attribution (CC BY) license (https:// creativecommons.org/licenses/by/ $4.0 /)$.

\begin{abstract}
Aiming at addressing the problems of high specific energy consumption for cutting and slow response to the change of hardness in the control of existing mining roadheaders, an adaptive variable speed cutting control method based on cutting performance optimization is proposed by analyzing the working principle of roadheaders. Firstly, cylinder pressure and motor current are invoked as the criteria to judge load changes. Particle swarm optimization is utilized to optimize the cutting parameters under different impedance. Then, the relation between cutting speed, motor current and cylinder pressure is established by using fuzzy neural network to train cutting parameters and identification parameters under different conditions. Finally, the vector control of motor and electro-hydraulic servo valve is used to control the cutting speed. The results show that the cutting unit can adapt to different load signals and always keep the roadheader in the optimal working state. The rotation speed regulation of the cutting head reaches the stable state after $0.05 \mathrm{~s}$, with the overshoot of $1.42 \%$. The swing speed regulation of the cutting head reaches the stable state after $1 \mathrm{~s}$, with the overshoot of $5.3 \%$. Conclusions provide a basis for improving the cutting efficiency and prolonging the working life of the roadheader.
\end{abstract}

Keywords: performance optimization; adaptive; fuzzy neural networks; SVPWM; servo valve

\section{Introduction}

The cutting unit bears a large load and impact load, and its power consumption accounts for about $75 \%$ of the total installed power. The cutting motor is often in the state of overload or underload because of the constant change of the cutting load which is caused by the complex and changeable physical characteristics of coal and rock. Therefore, it is necessary to dynamically adjust cutting speed according to the hardness of the coal and rock to maintain a high-efficiency cutting state [1,2]. The cutting performance of roadheader is mainly determined by structural parameters and cutting motion parameters [3]. The finite element method was used to establish the numerical model of rock cutting for investigating the variation laws of cutting force and debris size with cutting speed and rake angle $[4,5]$. Liu et al. [6] studied the influence of cutting angle on cutter wear and concluded that larger rake angle could reduce wear. Wang et al. [7] studied the effect of cutting depth on specific energy consumption for cutting and found that only $3 \%$ of external work is used to generate new chipping surfaces. By investigating the influence of cutting speed on cutting performance, Zhang et al. [8] explored the change rules of specific energy consumption for cutting and average cutting force with propelling speed and rotation speed.

The above research on cutting parameters and motion parameters can improve the cutting performance to a certain extent, but the performance can be further improved by adjusting the parameters according to the hardness of the coal. Yang et al. [9] used a proportional integral derivative (PID) control to maintain the power of the cutting machine motor constant by adjusting the speed of the hydraulic cylinder. Wang et al. [10] proposed a coal-rock dynamic identification method based on adaptive weight optimization and 
multi-sensor information fusion according to the differences in cutting current, vibration, acoustic emission, infrared thermal image and other signals at different cutting state. Faradonbeh et al. [11] established a database of machine performance and geomechanical parameters of rock. In order to obtain more accurate models for predicting the performance of roadheaders, they also analyzed the parameters through genetic programming (GP) and gene expression programming (GEP) approaches. Dolipski et al. [12] proposed an automatic cutting head speed control system with a PID controller to reduce the energy consumption of the cutting head. Wang et al. [13] established a multi-information feature library including $Y$-axis vibration signal, acoustic emission signal, cutting current signal and temperature signal to judge the hardness of coal and rock. Gao et al. [14] used the power supply panel as the controller to realize the automatic forming of the roadway section and the automatic traction and the speed regulation of the cutting arm. Wang et al. [15] proposed a control method to improve the speed of roadheader by using multi-sensor information fusion and solved the problem of low efficiency of roadheader by classifying the speed of cutting head to adapt to the change of coal and rock hardness. Zhao et al. [16] took the current as the control object and adjusted the motor speed by setting the rated current and using vector control to make the cutting motor operate at constant power. Cheluszka et al. [17] proposed a speed control mode of cutting head and compared the performance of the control system with and without speed feedback through experiments.

As stated previously, most studies on cutting performance focus on the design of cutting head, and the researches about motion parameters are also limited to specific loads, which leads to the inability of the roadheader to maintain the optimal cutting state in real time. Aiming at the above problem, this paper proposes an adaptive control method based on performance optimization to improve the cutting efficiency of roadheader.

The rest of the paper is structured as follows: The influences of cutting speed on loads are analyzed in Section 2. In Section 3, particle swarm optimization is utilized to calculate the cutting parameters with the best cutting performance. In Section 4, the fuzzy neural network is used to establish the mapping relationship between motor current, cylinder pressure and cutting speed to realize the hardness identification. The optimal cutting conditions under different loads are achieved by the above methods.

\section{The Establishment of Mathematical Models}

\subsection{Working Principle of Roadheader}

The front of the cantilever is the cutting head, which is driven by the motor to rotate the cutting head for crushing coal and rock, and the back part is connected with the revolving platform. The transverse swing process of the cantilever is driven by a pair of symmetrical rotary hydraulic cylinders. The cantilever can swing around its rotary center by extending one side of the hydraulic cylinder and synchronously shortening the other side. The cantilever vertical swing through a pair of lifting hydraulic cylinders at the same time telescopic or shortened. Its structural principle is shown in Figure 1.

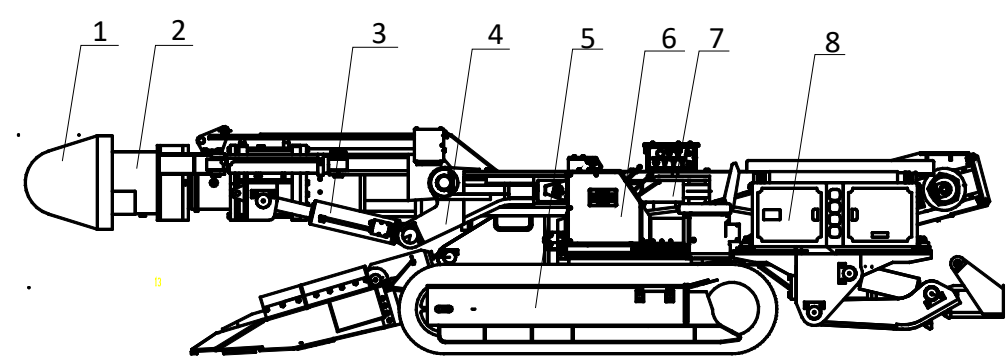

Figure 1. Structure diagram of roadheader. 1. Cutting head 2. Cutting arm 3. Lifting cylinders 4. Revolving platform 5. Travelling mechanism 6. Rack 7. Angling cylinders 8. Electrical system.

From the working principle and working process of roadheader as shown in Figure 2, the cutting performance is related to the swing speed and rotation speed of the cutting 
head. Therefore, it is necessary to establish the relationship between the speed of the hydraulic cylinder and the swing speed of the cutting head, as well as the influence of the swing speed $v$ and the rotation speed $n$ on the cutting load.

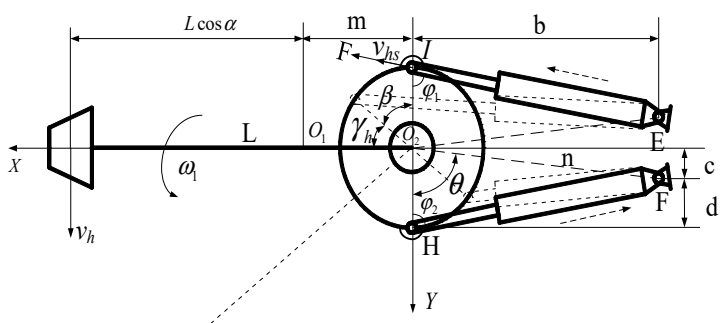

(a)

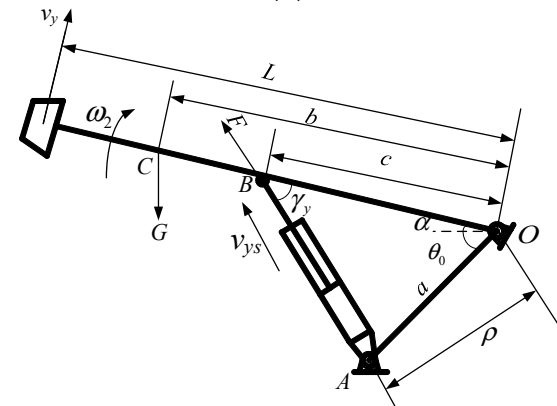

(b)

Figure 2. Schematic of cutting mechanism of roadheader: (a) horizontal swing; (b) lifting swing.

According to the working principle, the swing speed of the cutting head can be obtained as follows:

$$
\left\{\begin{array}{c}
v_{y}=L \omega_{1}=\frac{L \sin \gamma_{y}}{c} v_{y s} \\
v_{h}=(L \cos \alpha+m) \omega_{2}=\frac{1}{R}(L \cos \alpha+m) v_{h s} \sin \gamma_{h}
\end{array}\right.
$$

where $v_{y}$ is the lifting speed, $v_{h}$ is the swing speed; $L$ is the length of the cantilever; $\gamma$ is the transmission angle; $m$ is the distance between the projection point of the lifting center on the horizontal plane and the rotation center; $\alpha$ is the lifting angle; $v_{y s}$ and $v_{h s}$ are the speed of the lifting cylinder and the angling cylinder respectively.

\subsection{Roadheader Cutting Head Load}

The load of the cutting head is determined by the hardness of coal and rock and the cutting depth of the cutting teeth. Large loads and load fluctuations will cause the damage of the picks and decrease the working life of the roadheader $[18,19]$.

As shown in Figure 3, the force on the $i$-th pick can be decomposed into cutting resistance $Z_{i}$, tractive resistance $Y_{i}$ and side resistance $X_{i}$. The value of parameters in the load calculation formula is shown in Table 1 [20]. The pick information is shown in Table 2 [21].

$$
\left\{\begin{array}{c}
Z_{i}=P_{k}\left[k_{T} k_{g} k_{y}\left(0.25+0.018 t h_{i}\right)+0.1 S_{j}\right] \\
Y_{i}=Z_{i}\left(0.15+0.00056 P_{k}\right) 2.5 / h_{i}^{0.4} \\
X_{i}=Z_{i}\left(C_{1} /\left(C_{2}+h_{i}\right)+C_{3}\right) h_{i} / t
\end{array}\right.
$$

where $P_{k}$ is the contact strength of the coal and rock; $k_{T}, k_{g}$ and $k_{y}$ are the coefficient of type, the coefficient geometrical shape and the coefficient of chamfering of cutting pick; $t$ is the average transversal spacing; $h_{i}=(1000 \mathrm{v} / \mathrm{nm}) \sin \phi_{i}$ denotes the average cutting thickness, $m$ is the number of cutting pick on the same cutting line; $S_{j}$ is the projected area of cutting 
pick after blade surface in the traction direction; $C_{1}, C_{2}$ and $C_{3}$ are influence coefficients of breakout patterns.

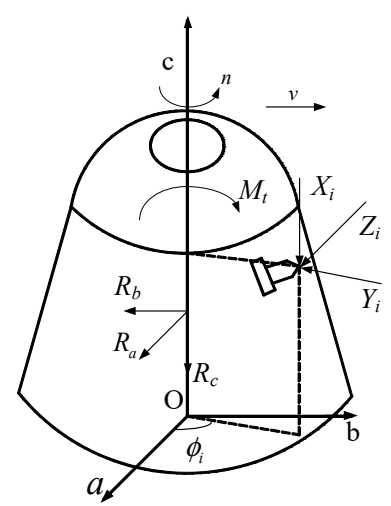

Figure 3. Force diagram of the cutting head.

Table 1. The value of parameters in the load calculation formula.

\begin{tabular}{cccccccccc}
\hline Parameter & $k_{T}$ & $k_{g}$ & $k_{y}$ & $t$ & $S_{j}$ & $C_{1}$ & $C_{2}$ & $C_{3}$ & $m$ \\
\hline Value & 1.5 & 1.221 & 0.65 & 30 & 20 & 1 & 0.2 & 0.1 & 3 \\
\hline
\end{tabular}

Table 2. Information of cutting pick.

\begin{tabular}{ccccccccccccc}
\hline Pick & $\mathbf{1}$ & $\mathbf{2}$ & $\mathbf{3}$ & $\mathbf{4}$ & $\mathbf{5}$ & $\mathbf{6}$ & $\mathbf{7}$ & $\mathbf{8}$ & $\mathbf{9}$ & $\mathbf{1 0}$ & $\mathbf{1 1}$ & $\mathbf{1 2}$ \\
\hline$\phi_{i}\left(^{\circ}\right)$ & 0 & 85 & 228 & 37 & 132 & 265 & 74 & 169 & 302 & 111 & 206 & 339 \\
$r_{i}(\mathrm{~mm})$ & 560 & 560 & 560 & 559 & 553 & 543 & 533 & 523 & 513 & 503 & 493 & 483 \\
\hline Pick & $\mathbf{1 3}$ & $\mathbf{1 4}$ & $\mathbf{1 5}$ & $\mathbf{1 6}$ & $\mathbf{1 7}$ & $\mathbf{1 8}$ & $\mathbf{1 9}$ & $\mathbf{2 0}$ & $\mathbf{2 1}$ & $\mathbf{2 2}$ & $\mathbf{2 3}$ & $\mathbf{2 4}$ \\
\hline$\phi_{i}\left(^{\circ}\right)$ & 148 & 243 & 16 & 185 & 280 & 53 & 222 & 317 & 90 & 259 & 354 & 127 \\
$r_{i}(\mathrm{~mm})$ & 473 & 464 & 455 & 446 & 437 & 428 & 419 & 410 & 399 & 386 & 371 & 354 \\
\hline Pick & $\mathbf{2 5}$ & $\mathbf{2 6}$ & $\mathbf{2 7}$ & $\mathbf{2 8}$ & $\mathbf{2 9}$ & $\mathbf{3 0}$ & $\mathbf{3 1}$ & $\mathbf{3 2}$ & $\mathbf{3 3}$ & $\mathbf{3 4}$ & $\mathbf{3 5}$ & $\mathbf{3 6}$ \\
\hline$\phi_{i}\left({ }^{\circ}\right)$ & 296 & 33 & 166 & 338 & 81 & 215 & 31 & 146 & 280 & 95 & 217 & 356 \\
$r_{i}(\mathrm{~mm})$ & 335 & 315 & 294 & 270 & 247 & 222 & 195 & 168 & 140 & 110 & 80 & 50 \\
\hline
\end{tabular}

The vertical force $R_{a}$, traversing force $R_{b}$, axial force $R_{c}$ and load torque $M_{t}$ in the cutting head can be expressed as:

$$
\left\{\begin{array}{c}
R_{a}=\sum_{i}^{j}\left(Z_{i} \sin \phi_{i}-Y_{i} \cos \phi_{i}\right) \\
R_{b}=\sum_{i}^{j}\left(Z_{i} \cos \phi_{i}+Y_{i} \sin \phi_{i}\right) \\
R_{c}=\sum_{i}^{j} X_{i} \\
M_{t}=\sum_{i}^{j} Z_{i} r_{i}
\end{array}\right.
$$

where $\phi_{i}$ is the position angle of a single cutting pick; $r_{i}$ is the working radius of the $i$-th pick, $j$ is the number of picks which participate in cutting at this moment.

In Figure $4 \mathrm{a}$, the three-way force load presents periodic variation and the sequence from high to low is $R_{a}, R_{b}, R_{c}$. In Figure $4 \mathrm{~b}, \mathrm{c}$, the load and torque decrease with the increase of the rotational speed and increase with the growth of the swing speed. According to the analysis, the impact caused by the abrupt change in hardness can be reduced by decreasing the swing speed and increasing the rotation speed. 


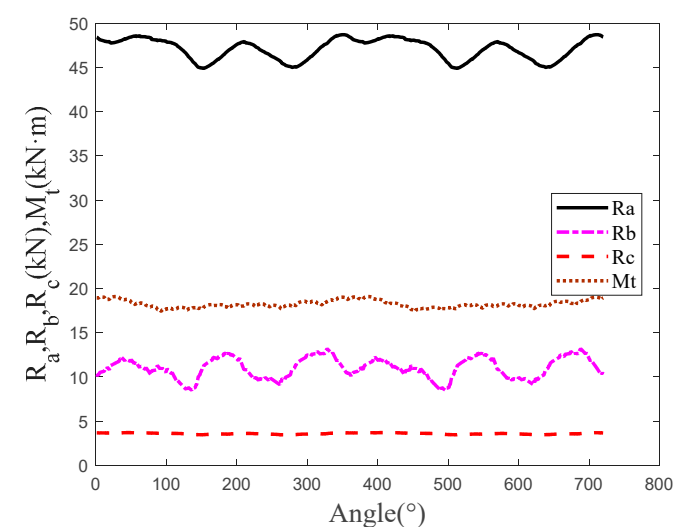

(a)

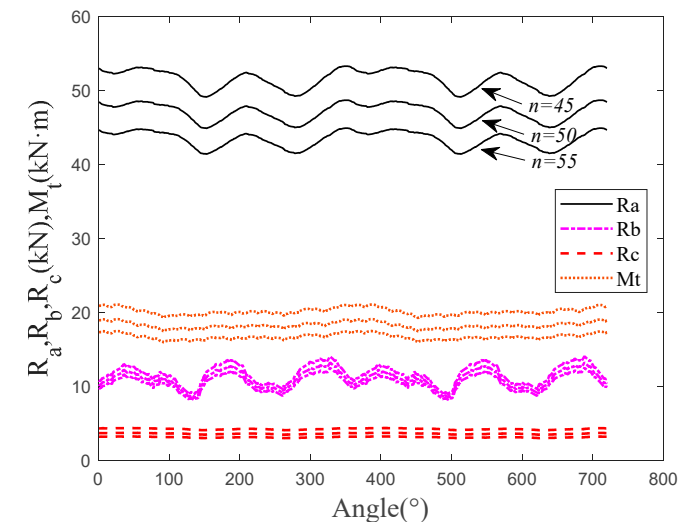

(b)

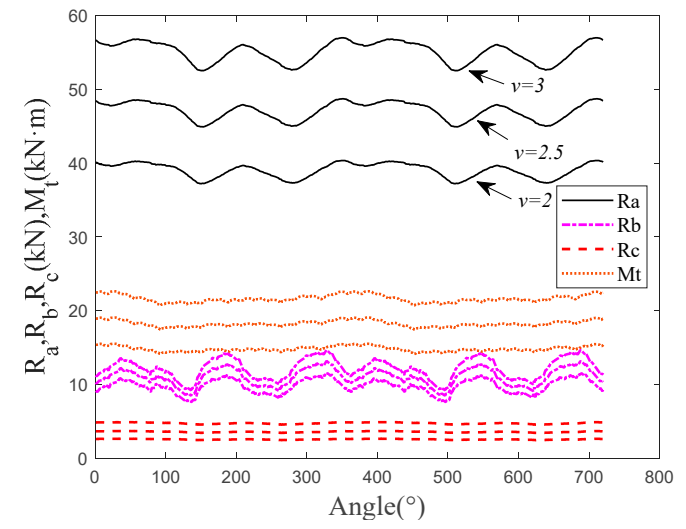

(c)

Figure 4. Influence of cutting parameters on cutting head load: (a) loading curve at $P_{k}=350$ and (b) the load comparison curve at different rotating speeds and (c) the load comparison curve at different swinging speeds.

\subsection{Establishment of Coal and Rock Load Identification Database}

The identification of the hardness of coal and rock is the premise of adjusting the cutting parameters. By collecting the current of motor and the pressure of cylinder under different loads, the load identification database can be established.

The relationship between load torque and current is:

$$
I_{l}=\frac{M_{t} n}{9550 \times \sqrt{3} U_{l} \eta \cos \varphi}
$$

The effect of vertical force on the pressure of the lifting cylinder is expressed as:

$$
P=\frac{R_{a} L+G b \cos \alpha}{2 A c \sin \gamma}
$$

The effect of traversing force on the pressure of the rotary cylinder is denoted as:

$$
P_{1}=\frac{R_{b}(L \cos \alpha+m)}{A_{1} R \sin \varphi_{1}+R A_{2} \sin \varphi_{2}}
$$

where $U_{l}$ is the line voltage of motor; $I_{l}$ is the line current of motor; $\eta=0.9$ represents transmission efficiency of the reducer; $\cos \varphi$ refers to the motor power factor; $P$ and $P_{1}$ are the pressure of lifting cylinder and the rotary cylinder; $A, A_{1}$ and $A_{2}$ are the working area of cylinder; $\varphi_{1}, \varphi_{2}$ is the angle between the oil cylinder and the two hinge points. 
From Equations (4)-(6) it can be observed that the current of the cutting motor and the pressure of the cylinder are related to the load. Hence, the impedance of coal and rock can be identified by establishing the relationship between current, pressure and impedance.

The relationship between motor current and cylinder pressure and load is shown in Figure 5. The analysis shows that the current of the cutting motor and the pressure of the driving cylinder are consistent with the changes of the cutting load. The feasibility of this method is proved by the above research. The impedance identification database was established as shown in Table 3.

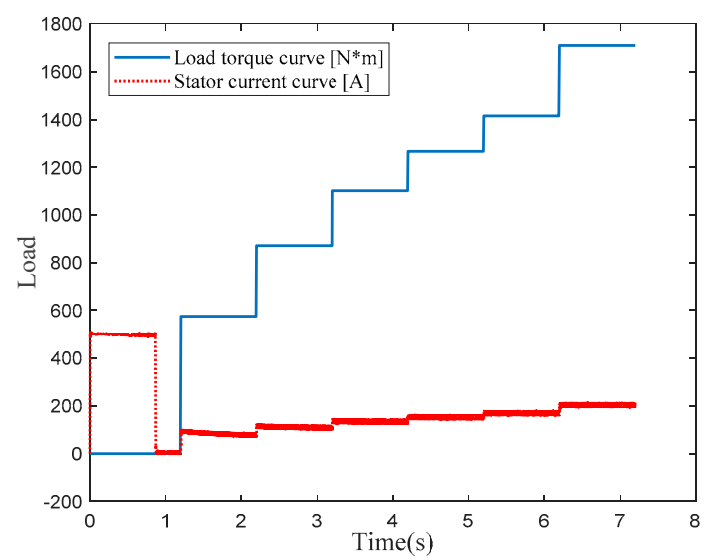

(a)

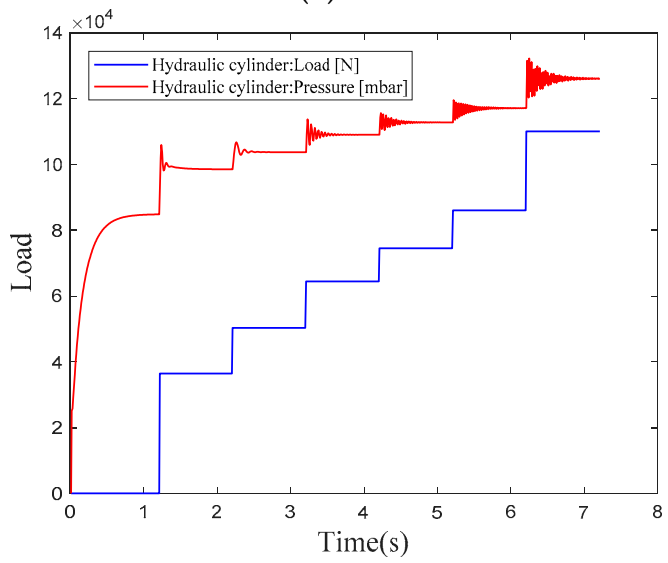

(b)

Figure 5. (a) Current change curves under different loads and (b) Pressure change curve under different loads.

Table 3. Coal and rock impedance identification database.

\begin{tabular}{ccccccc}
\hline $\boldsymbol{P}_{\boldsymbol{k}}(\mathbf{M P a})$ & $\mathbf{3 5 0}$ & $\mathbf{4 9 0}$ & $\mathbf{6 5 0}$ & $\mathbf{8 0 0}$ & $\mathbf{1 0 0 0}$ & $\mathbf{1 3 0 0}$ \\
\hline Current (A) & 96 & 105 & 133 & 156 & 170 & 203 \\
Pressure (MPa) & 9.8 & 10.3 & 10.8 & 11.28 & 11.73 & 12.6 \\
\hline
\end{tabular}

\section{Cutting Parameter Optimization}

\subsection{Cutting Parameter Optimization Do Not Use the Same Titles}

The cutting performance depends on the structural parameter and cutting parameters during the cutting process of the roadheader. The structural parameters were fixed at the beginning of the design, the cutting performance can only be improved by changing the swing speed $v$ and the rotation speed $n$ [22]:

(1) Determination of design variables 
The swing $(v)$, and rotation $(n)$ speeds were selected as the optimized variables, then the optimized variables is described as:

$$
X=\left[x_{1}, x_{2}\right]^{T}=[v, n]^{T}
$$

(2) Objective function establishment

The fluctuation coefficient of three-direction load and torque $M_{t}$, and specific energy consumption for cutting $H_{w}$ are used as the objective function for optimization of the cutting performance. The fluctuation coefficients of the three-direction load is:

$$
K_{R_{g}}=\frac{1}{\bar{R}_{g}} \sqrt{\frac{1}{N} \sum_{i=1}^{N}\left(R_{g i}-\bar{R}_{g}\right)^{2}}
$$

The fluctuation coefficients of torque is denoted as:

$$
K_{M_{t}}=\frac{1}{\bar{M}_{t}} \sqrt{\frac{1}{N} \sum_{i=1}^{N}\left(M_{t i}-\bar{M}_{t}\right)^{2}}
$$

The specific energy consumption for cutting is as follows:

$$
H_{w}=\frac{2 \pi n M_{t}}{3600 \lambda A v}
$$

where $N$ is the number of discrete points; $R_{g i}$ and $M_{t i}$ are the discrete value of load; $\bar{R}_{g}$ and $\bar{M}_{t}$ are the average value of load; $\lambda$ is the bulk density of coal and rock; $A$ is the area of the cutting head that participates in the cutting part perpendicular to the yaw direction.

For the multi-objective optimization design, the multiple objectives is transformed into several single objectives by using the linear weighting algorithm expressed as:

$$
F(X)=k_{1} f_{R_{a}}(X)+k_{2} f_{R_{b}}(X)+k_{3} f_{R_{c}}(X)+k_{4} f_{M_{t}}(X)+k_{5} f_{H_{w}}(X)
$$

where $k_{1}, k_{2}, k_{3}, k_{4}$ and $k_{5}$ are the optimal weight coefficients of each objective function, $f_{R_{a}}(X), f_{R_{b}}(X), f_{R_{c}}(X)$ and $f_{M_{t}}(X)$ are three-direction load and torque fluctuation coefficients, $f_{H_{w}}(X)$ is the minimum objective function of $H_{w}$.

(3) Analysis of optimization results

Regarding the power and speed range of the cutting motor as constraints, the cutting parameters of roadheader are optimized by the particle swarm algorithm to obtain the best rotation speed and swing speed under different hardness [23]. The optimized result is shown in Table 4. Table 5 shows the optimized motion parameters.

Table 4. Comparison of optimization results for $P_{k}=350$.

\begin{tabular}{cccccccc}
\hline $\boldsymbol{P}_{\boldsymbol{k}}=350(\mathrm{MPa})$ & $\boldsymbol{N}(\mathrm{r} / \mathrm{min})$ & $\boldsymbol{V}(\mathrm{m} / \mathrm{min})$ & $K_{\boldsymbol{R}_{a}}$ & $K_{\boldsymbol{R}_{b}}$ & $K_{\boldsymbol{R}_{c}}$ & $K_{\boldsymbol{M}_{t}}$ & $\boldsymbol{H}_{\boldsymbol{W}}\left(\mathbf{k W} \cdot \mathbf{h} / \mathbf{m}^{3}\right)$ \\
\hline $\begin{array}{c}\text { Before } \\
\text { optimization }\end{array}$ & 50 & 2.5 & 0.0117 & 0.0612 & 0.0236 & 0.0106 & 1.017 \\
$\begin{array}{c}\text { After } \\
\text { optimization }\end{array}$ & 48.28 & 2.43 & 0.011 & 0.0583 & 0.0215 & 0.0102 & 0.9136 \\
\hline
\end{tabular}

Table 5. Motion parameters after optimization.

\begin{tabular}{ccccccc}
\hline $\left.\boldsymbol{P}_{\boldsymbol{k}} \mathbf{( M P a}\right)$ & $\mathbf{3 5 0}$ & $\mathbf{4 9 0}$ & $\mathbf{6 5 0}$ & $\mathbf{8 0 0}$ & $\mathbf{1 0 0 0}$ & $\mathbf{1 3 0 0}$ \\
\hline$N(\mathrm{r} / \mathrm{min})$ & 48.28 & 43.96 & 40.15 & 38 & 36.91 & 34.17 \\
$V(\mathrm{~m} / \mathrm{min})$ & 2.43 & 2.18 & 1.92 & 1.7 & 1.508 & 1.38 \\
\hline
\end{tabular}


Compared with the traditional power control method, the fluctuation coefficient of the optimized forces in three directions is reduced by $5.98 \%, 4.73 \%$ and $8.89 \%$ respectively; the fluctuation coefficient of load torque is reduced by $3.77 \%$; the specific energy consumption for cutting is reduced by $10.16 \%$. This method can effectively improve the cutting efficiency of the roadheader.

\subsection{Adaptive Variable Speed Cutting Control Strategy for Roadheader}

The voltage and current of the cutting motor and the pressure of the driving cylinder vary with the hardness of coal and rock. Hence, the current and pressure are used as identification criteria in this strategy. Using the swing speed $v$ and the rotational speed $n$ of the cutting head as the control targets, the fuzzy neural network is used to ensure that roadheader performs the optimal working state. In the control process, the real-time detection equipment (RTDE) collects the current $I$ of the cutting motor and the pressure $P$ of the driving cylinder, then $I$ and $P$ are employed as the input parameters of the fuzzy neural network. The optimal cutting parameters are output by the neural network under the under specific conditions of hardness. PID is used to reduce the deviation signal that is the difference between the optimization parameters $v_{1}$ and $n_{1}$ and the feedback signals $v$ and $n$. Control signals are tracked by electro-hydraulic servo valves (EHSV) and inverter to achieve optimal cutting state as shown in Figure 6.

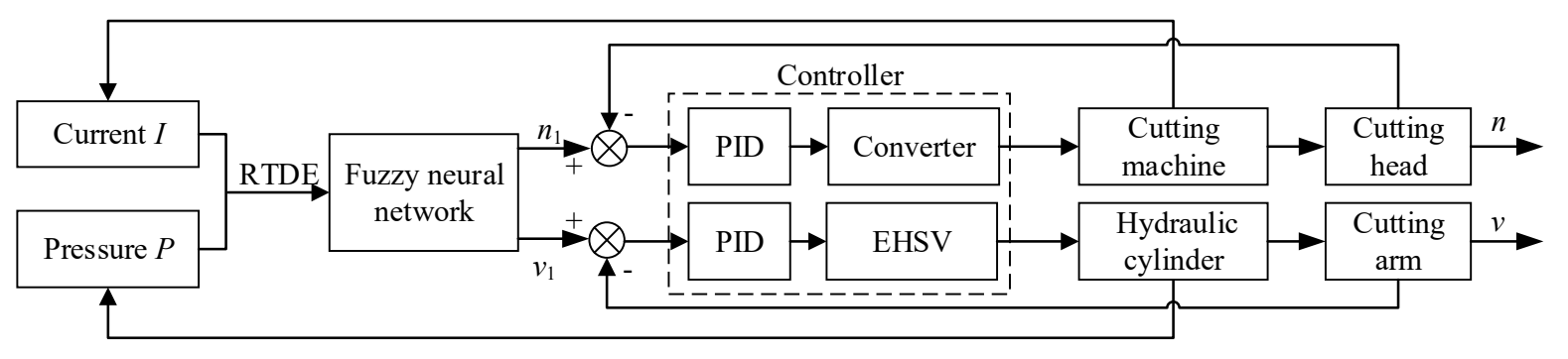

Figure 6. Adaptive variable speed cutting control strategy diagram.

\subsection{Fuzzy Neural Recognition of Coal and Rock Impedance}

As shown in Figure 7, two neurons in the input layer of the neural network correspond to the current $I$ and the pressure $P$ respectively. The output of the neural network is the swing speed or rotational speed that has been optimized [24].

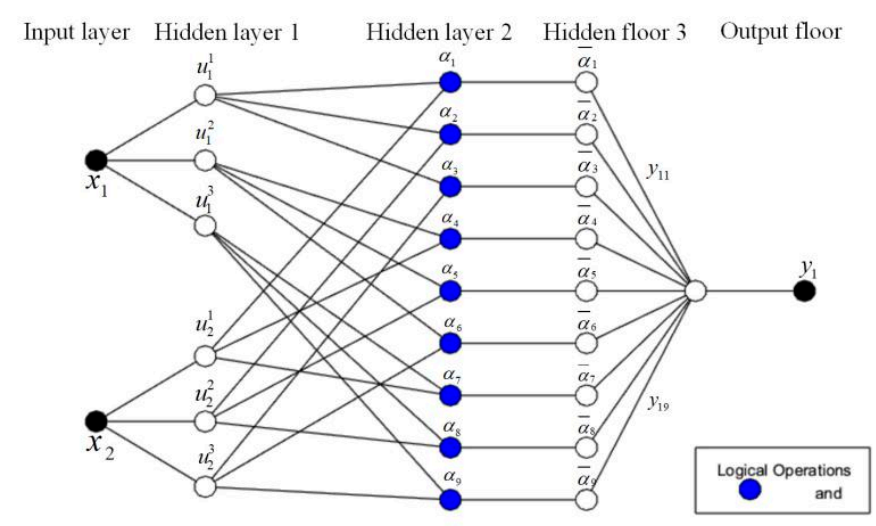

Figure 7. Fuzzy neural network structure diagram. 
The network adopts the triangle function as the membership function. The first layer of the sub-network is the input layer. The second layer is the hidden layer, which is used to calculate the result of three nodes.

$$
y_{i j}=p_{j 0}^{i}+p_{j 1}^{i} x_{1}+\cdots+p_{j n}^{i} x_{n}=\sum_{l=1}^{n} p_{j l}^{i} x_{l}
$$

The third layer is the output of the system:

$$
y_{i}=\sum_{j=1}^{m} \bar{\alpha}_{j} y_{i j}
$$

where $\bar{\alpha}_{j}$ is the normalization of fitness, that is the calculation of the second layer to the third layer $\bar{\alpha}_{j}=\alpha_{j} / \sum_{i=1}^{m} \alpha_{i}$.

The 500 groups of training data were collected in Sections 2 and 3, the 6 groups of data in Table 3 were used as test data. The training results are shown in Figure 8.

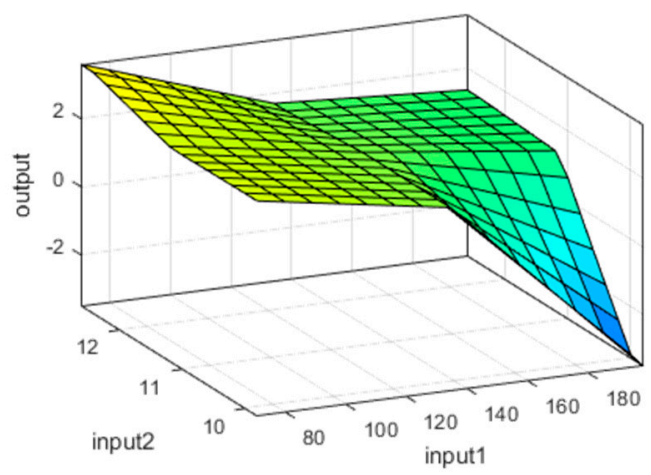

(a)

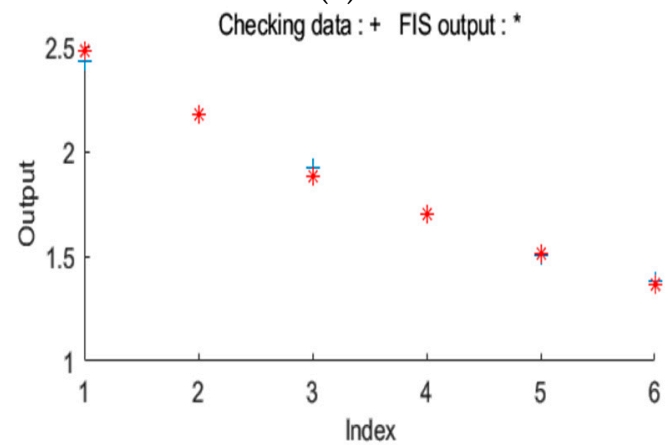

(b)

Figure 8. The results of neural network training of swing speed (a) output surface after fuzzy neural network training and (b) comparison diagram of verification data and network output data.

In Figure 8, input1 is the cutting motor current, and input2 is the rotary cylinder pressure. The data in Table 5 is considered as checking data, and the FIS output is the data trained by the fuzzy neural network. In Figure $8 \mathrm{a}$, the output of swing speed is gradually decreasing with the increase of current $I$ and pressure $P$. The maximum of swing speed is $2.55 \mathrm{~m} / \mathrm{min}$ and the minimum is $1.36 \mathrm{~m} / \mathrm{min}$. As the changing trend of current and pressure in the actual work is consistent, the lack of training data with different changing trends leads to negative values in the training results in Figure 8a. Figure $8 \mathrm{~b}$ is the comparison of the detection parameters and output parameters of the fuzzy nerve. The comparison shows that the output results are almost the same as the actual optimization results. The maximum error value of the two is 0.0446 which satisfies the requirements of the impedance identification controller. 


\section{Adaptive Control Simulation of Roadheader}

From Tables 2 and 3 , we can see that the speed $n$ of cutting head alters from $43.96 \mathrm{r} / \mathrm{min}$ to $38 \mathrm{r} / \mathrm{min}$ when the coal and rock hardness changes from $P_{k}=490$ to $P_{k}=800$, and the speed $v$ of cutting head changes from $2.18 \mathrm{~m} / \mathrm{min}$ to $1.7 \mathrm{~m} / \mathrm{min}$. Current and pressure also change with $P_{k}$. The speed of cutting motor is controlled by SVPWM as shown in Figure $9[25,26]$.

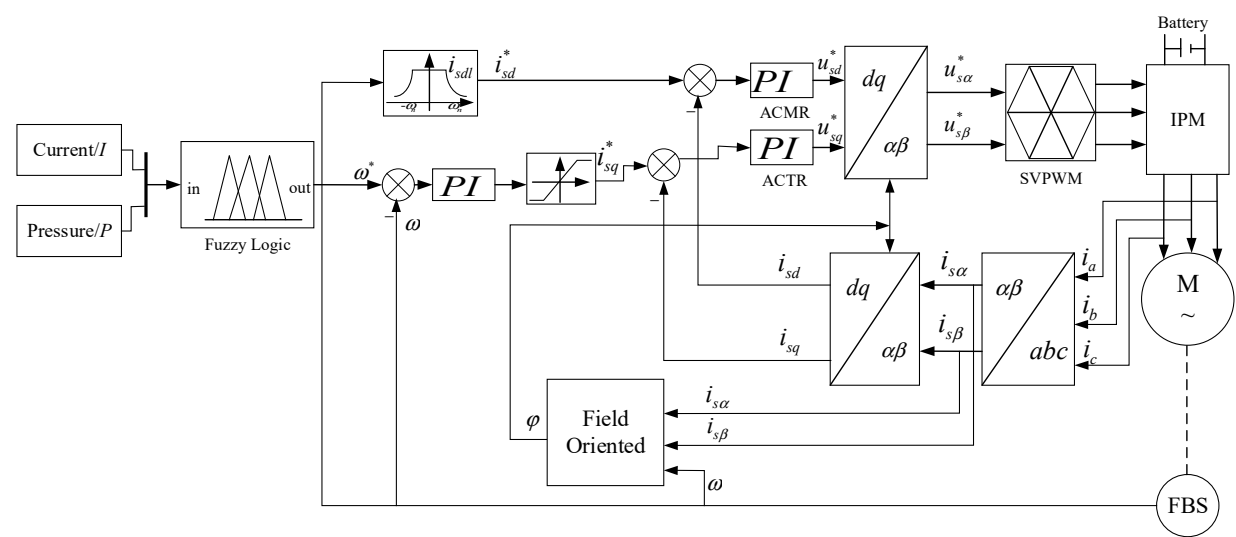

Figure 9. Cutting motor Simulink model.

As shown in Figure 10, the motor reaches the rated speed at about $0.6 \mathrm{~s}$. The cutting speed decreases from $1485 \mathrm{r} / \mathrm{min}$ to $1406 \mathrm{r} / \mathrm{min}$ when the time reaches $0.7 \mathrm{~s}$. The cutting head speed decreases to $1215 \mathrm{r} / \mathrm{min}$ when the hardness of coal and rock changes again. The maximum overshoot of the system was $1.06 \%$ and the response time was $0.05 \mathrm{~s}$.

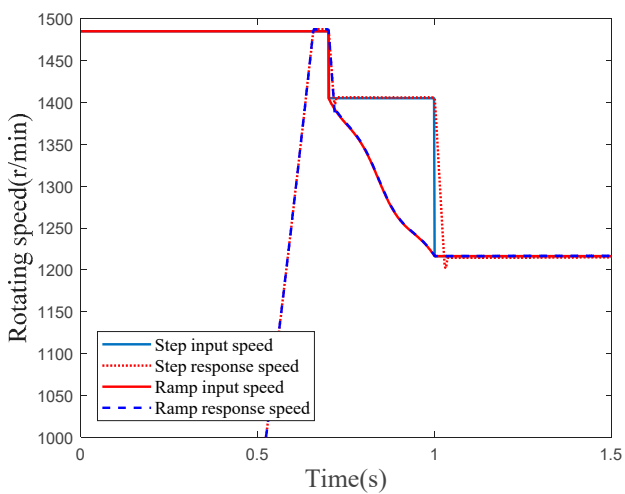

(a)

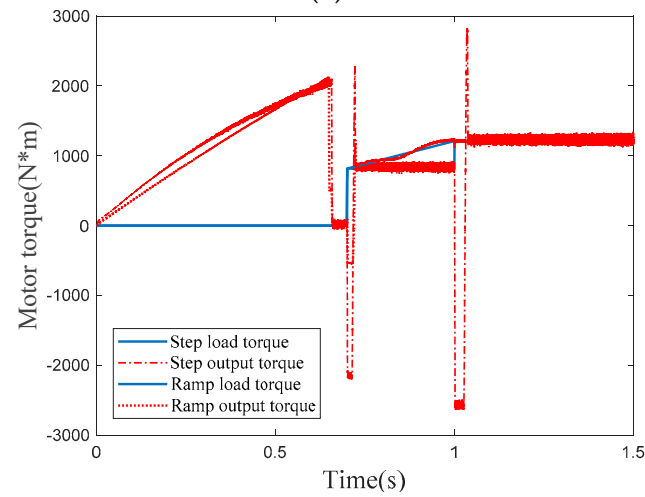

(b)

Figure 10. Torque and speed response curves under different signals: (a) torque response and (b) rotating speed response. 
In the starting stage, the maximum torque is $2081 \mathrm{Nm}$ and the maximum current is $500 \mathrm{~A}$. The change trend of stator current is consistent with that of cutting load. The simulation results show that the effect of vector control is relatively ideal for both step signal and ramp signal. The vector control can quickly adjust the motor speed to ensure that it can reach the optimal cutting parameters output by neural network when the hardness of coal rock changes.

The fluctuation occurs in the ramp signal because of the approximate linear relationship between the rotation speed and the impedance of coal and rock. In Figure 11, the change of stator current can reflect the change of coal and rock impedance which verifies the feasibility of current as the identification criteria again.

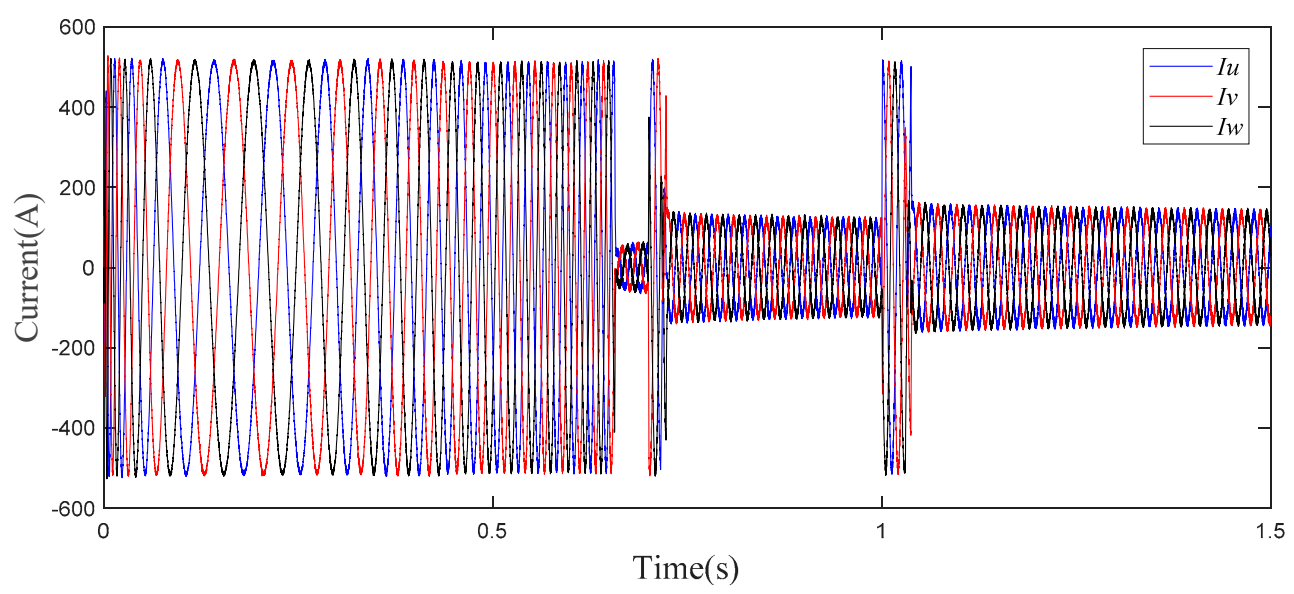

Figure 11. Step signal stator current.

The swing speed $v$ of cantilever is determined by current and pressure signals of system. Then, the deviation signal $\Delta v$ is obtained by comparing the output speed of network with the feedback speed of system. Deviation signal $\Delta v$ controls the current $I$ of valve through correction, amplification and other links. Current controls the opening size and direction of the electro-hydraulic servo valve to control the cantilever swing of the roadheader $[27,28]$.

The parameters of the hydraulic system are set as follows: $\mathrm{D}=180 \mathrm{~mm}$, where $\mathrm{D}$ represents the inner diameter of hydraulic cylinder; D1 $=100 \mathrm{~mm}$ is the hydraulic rod diameter; $\mathrm{F}=35 \mathrm{MPa}$ denotes the opening pressure of the relief valve; $\mathrm{F} 1=1.5 \mathrm{MPa}$ express the pressure drop of the electro-hydraulic servo valve. The control effect of traditional PID and fuzzy PID under step and ramp load signals is compared. The deviation between the input speed and the output speed of the hydraulic system is selected as the optimization objective. The range of PID parameters is given by the optimizer in AMESim, and the genetic algorithm is selected to optimize the target to obtain the optimal PI value of the traditional PID control. The simulation model is shown in Figure 12.

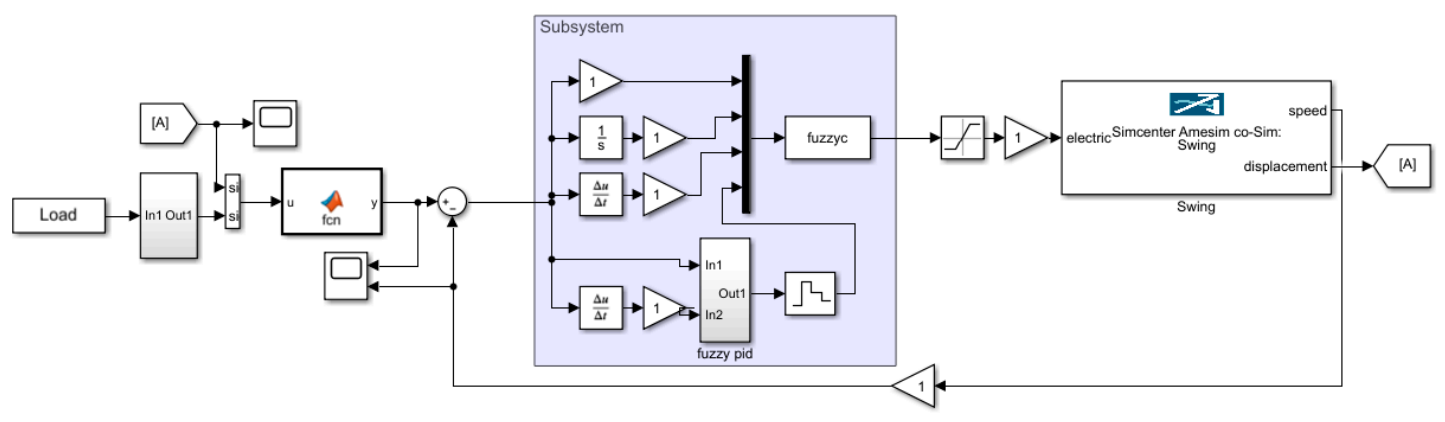

Figure 12. Co-simulation model of AMESim and Simulink. 
According to the simulation results shown in Figure 13, the fuzzy PID control effect is better than the traditional PID because its response time and overshoot are small. The fuzzy PID control was stabilized after $1 \mathrm{~s}$ and the maximum overshooting was $5.3 \%$. Furthermore, the cutting parameters can be automatically adjusted according to different input signals to make the roadheader always in an efficient cutting state. Through the simulation of a single control mode, it can be concluded that the vector control of the motor and the servo valve of the hydraulic system have a better control effect on the cutting state. Furthermore, by using the output parameters of the fuzzy neural network, the cutting state of motor and hydraulic system can be adjusted effectively.

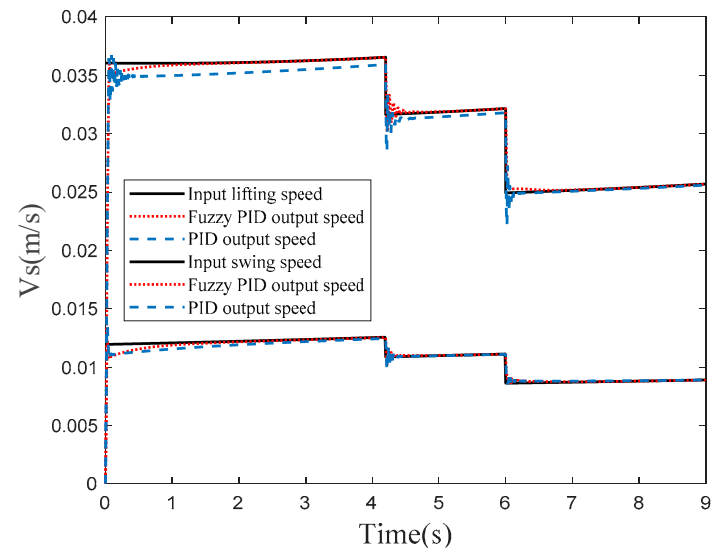

(a)

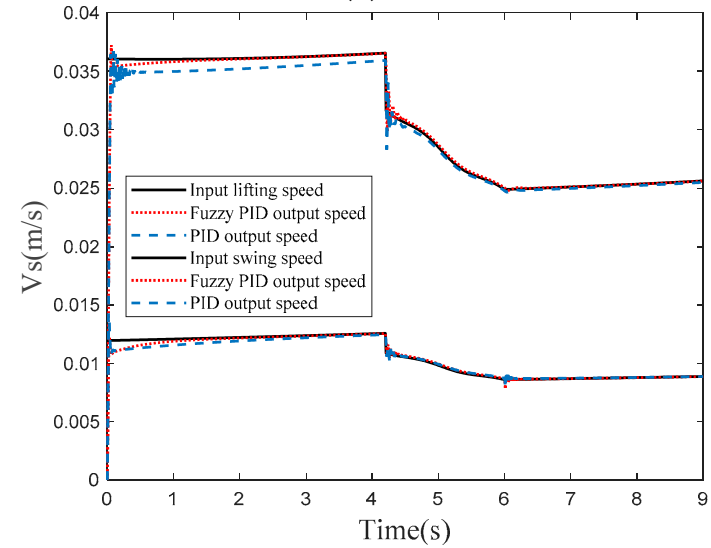

(b)

Figure 13. Speed response curves under different signals: (a) step signal response and (b) ramp signal response.

In practice the hydraulic system and the motor system always work together, so it is significant to carry out the joint simulation experiment. Figure 14 shows the co-simulation model and Figure 15 is the result of the simulation. Figure 15a shows that the motor speed deviates greatly from the optimization speed between $1 \mathrm{~s}$ and $3 \mathrm{~s}$, which is caused by the current and pressure fluctuations at this time. The motor reaches a stable running state after $3 \mathrm{~s}$, and the motor speed is basically consistent with the optimized speed at this moment. In Figure 15b, the hydraulic system fluctuates because the motor current signal and the hydraulic cylinder pressure signal are constantly changing. Similarly, there is a large deviation between the swing speed and the optimized speed between $1 \mathrm{~s}$ and $3 \mathrm{~s}$. The swing speed of the cutting head is basically consistent with the optimization speed after $3 \mathrm{~s}$, and the overall change trend is the same as the motor running condition. 


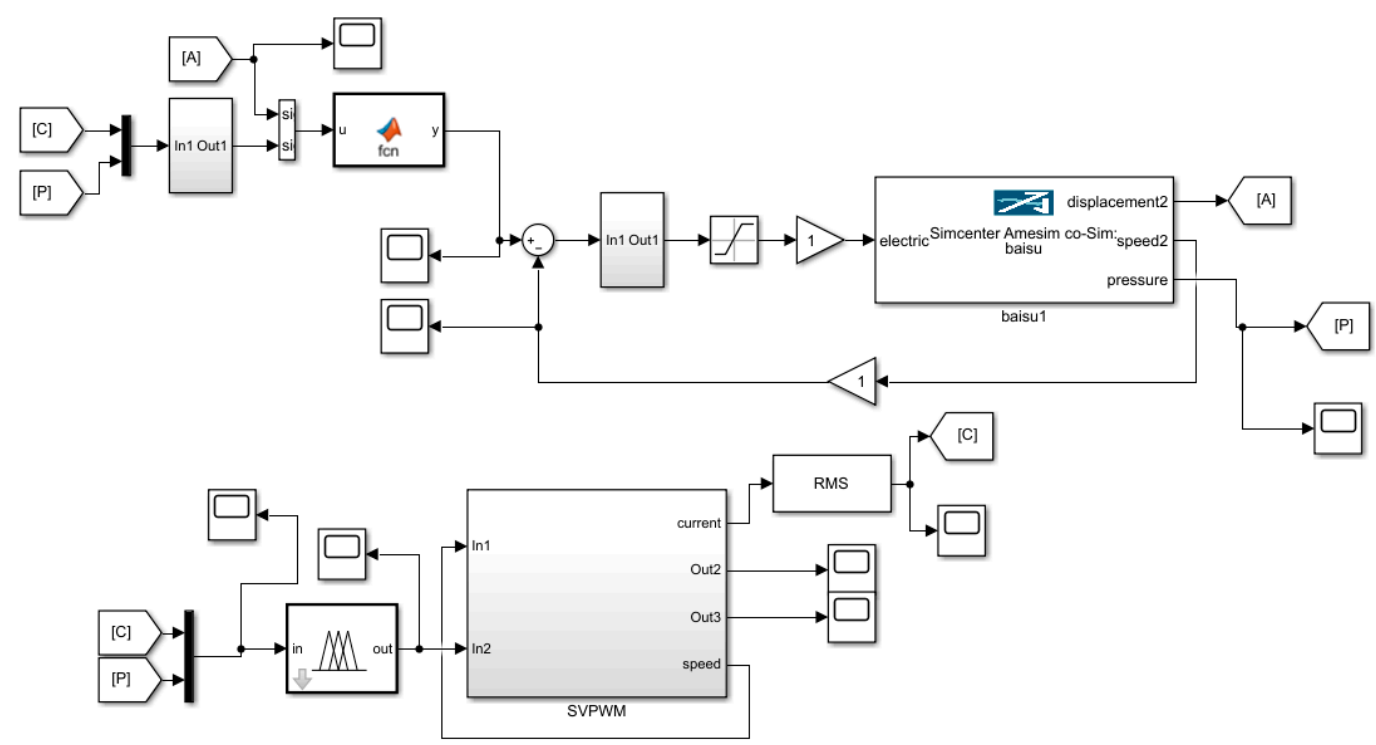

Figure 14. Co-simulation model of hydraulic system and electrical system.

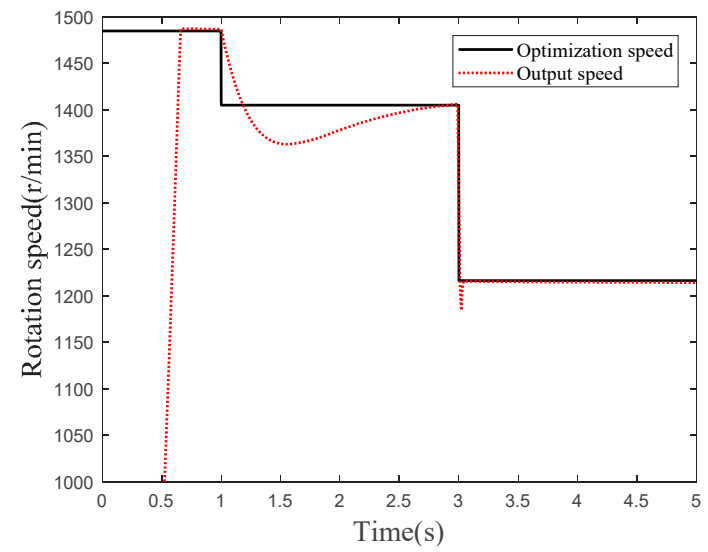

(a)

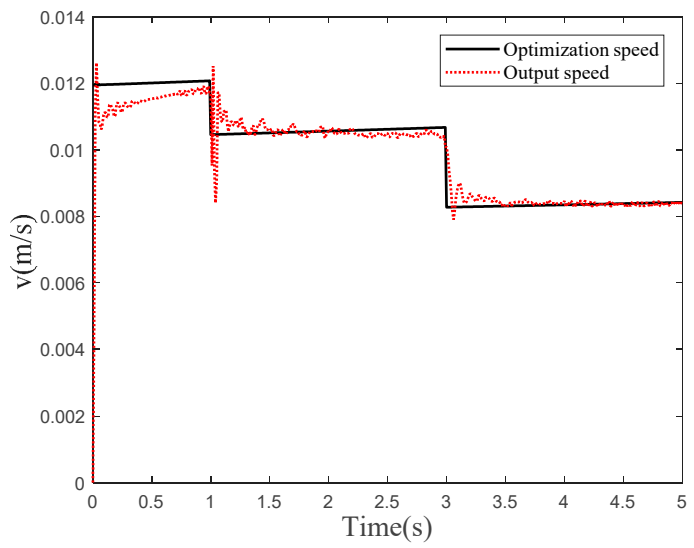

(b)

Figure 15. Swing speed and rotational speed results under co-simulation: (a) Comparison between the working state and the optimized state of the cutting motor and (b) Comparison of working state and optimal state of hydraulic system.

Through the above simulations of the single control mode and the joint control mode, it can be found that the optimal cutting parameters under the hardness can be output by the fuzzy neural controller by collecting the current and pressure signals. The roadheader 
has been in the efficient cutting state through the motor vector control and servo valve to trace the network output parameters. Therefore, the control method proposed in this paper can realize adaptive control of a roadheader and improve cutting performance.

\section{Conclusions}

In order to improve the cutting efficiency of a roadheader, the cutting speed is determined as the variable for the optimization by analyzing the working principle of it. For this purpose, motor current and cylinder pressure are selected as identification criteria. The mapping relationship between optimization variables and identification criteria is established through fuzzy neural network. The following conclusions can be drawn from the results obtained in this study.

The influence of different motion parameters for load variation was obtained by simulating the cutting head load of roadheader. The load of cutting head decreases with the increase of rotating speed and with a decrease of swinging speed.

Load fluctuation and the specific energy consumption for cutting were selected as the optimization objectives and the cutting parameters were taken as the optimization variables. By analyzing the optimization results, it is found that the load fluctuation is reduced and the specific energy consumption for cutting is decreased by $10.16 \%$.

The control method can automatically adjust the rotation speed of the cutting head and the swing speed of the cutting arm to adapt to load changes and ensure the cutting mechanism in a highly efficient working state.

Author Contributions: Conceptualization, Q.L. and C.L.; methodology, C.L. and T.L.; software, C.L.; validation, Q.L., T.L. and Z.X.; formal analysis, C.L.; investigation, C.L.; resources, Q.L.; writingoriginal draft preparation, C.L.; writing-review and editing, T.L. All authors have read and agreed to the published version of the manuscript.

Funding: This research was funded by Anhui Science and Technology Major Project (201903a05020029), the University Synergy Innovation Program of Anhui Province (GXXT-2019-048) and Open Project of Anhui Province Key Laboratory of Special and Heavy Load Robot (TZJQR006-2021).

Institutional Review Board Statement: Not applicable.

Informed Consent Statement: Not applicable.

Data Availability Statement: Not applicable.

Conflicts of Interest: The authors declare no conflict of interest.

\section{References}

1. Mężyk, A.; Pawlak, M.; Kania, J.; Klein, W. A new concept of vibration-control system in continuous miner machine. Adv. Mech. Eng. 2019, 11. [CrossRef]

2. Peinsitt, T.; Haubmann, H.; Kargl, H.; Kary, C. Recent developments towards Autonomous Tunneling and Mining Machinery. In Tunnels and Underground Cities: Engineering and Innovation Meet Archaeology, Architecture and Art: Volume 6: Innovation in Underground Engineering, Materials and Equipment-Part 2; Taylor \& Francis Ltd: Oxfordshire, UK, 2020; pp. $2849-2858$.

3. Deshmukh, S.; Raina, A.K.; Murthy, V.M.S.R.; Trivedi, R.; Vajre, R. Roadheader-A comprehensive review. Tunn. Undergr. Sptech. 2020, 95. [CrossRef]

4. Menezes, P.L. Influence of rock mechanical properties and rake angle on the formation of rock fragments during cutting operation. Int. J. Adv. Manuf. Tech. 2017, 90, 127-139. [CrossRef]

5. Menezes, P.L. Influence of cutter velocity, friction coefficient and rake angle on the formation of discontinuous rock fragments during rock cutting process. Int. J. Adv. Manuf. Tech. 2017, 90, 3811-3827. [CrossRef]

6. Liu, X.; Tang, P.; Geng, Q.; Li, X.; Tian, M. Numerical research on wear mechanisms of conical cutters based on rock stress state. Eng. Fail. Anal. 2019, 97, 274-287. [CrossRef]

7. Wang, X.; Su, O. Specific energy analysis of rock cutting based on fracture mechanics: A case study using a conical pick on sandstone. Eng. Fract. Mech. 2019, 213, 197-205. [CrossRef]

8. Zhang, D.; Liu, S.; Jia, J. Influence of Motion Parameters on Cutting Performance of Boom-Type Roadheader during the Swing Cutting. Arab. J. Sci. Eng. 2020, 1-11. [CrossRef]

9. Yang, W.L.; Wang, Z.B.; Yan, B.L. Research on the Adaptive Cutting Method of Roadheader. Appl. Mech. Mater. 2013, 268, 1436-1439. [CrossRef] 
10. Wang, H.; Zhang, Q. Dynamic identification of coal-rock interface based on adaptive weight optimization and multi-sensor information fusion. Inform Fusion. 2019, 51, 114-128. [CrossRef]

11. Faradonbeh, R.S.; Salimi, A.; Monjezi, M.; Ebrahimabadi, A.; Moormann, C. Roadheader performance prediction using genetic programming (GP) and gene expression programming (GEP) techniques. Environ. Earth. Sci. 2017, 76, 1-12. [CrossRef]

12. Dolipski, M.; Cheluszka, P.; Sobota, P. Investigating the simulated control of the rotational speed of roadheader cutting heads, relating to the reduction of energy consumption during the cutting process. J. Min. Sci. 2015, 51, 298-308. [CrossRef]

13. Wang, H.; Lu, S.; Huang, M.; Zhao, X. Hardness identification of rock based on multi-sensor information fusion during the process of roadway tunnelling. Bull. Pol. Acad Sci. Tech. Sci. 2020, 1301-1309. [CrossRef]

14. Gao, J.; Wang, S.Y.; Li, R.; Zhu, X.P.; Gao, F.; Du, Y.B.; Wu, M. Design of new-type electric control system based on power panel and PCC for boom-type roadheader. IEEE Int. Conf. Mech. Autom. Control Eng. 2011, 1202-1205. [CrossRef]

15. Wang, P.; Shen, Y.; Li, R.; Zong, K.; Fu, S.; Wu, M. Multisensor information-based adaptive control method for cutting head speed of roadheader. Proc. Inst. Mech. Eng. Part C: J. Mech. Eng. Sci. 2020. [CrossRef]

16. Zhao, J.; Yu, Z.; Ren, S. The space vector control system design of the cross section cutting based on the fuzzy PID algorithm in the coal mine. IEEE Int. Conf. Mech. Autom. 2016, 743-747. [CrossRef]

17. Cheluszka, P.; Sobota, P.; Głuszek, G. Studies of behaviour of the automatic control system of roadheader cutting heads movement. MATEC Web Conf. EDP Sci. 2019. [CrossRef]

18. Shi, H.; Dong, X.; Zhang, N.; Ding, N. Research of Dynamic Load Identification for Rock Roadheader. IEEE Proc. Int. Conf. Prog. Inf. Comput. 2018, 158-162. [CrossRef]

19. Li, X.; Huang, B.; Ma, G.; Zeng, Q. Study on roadheader cutting load at different properties of coal and rock. Sci. World J. 2013. [CrossRef]

20. Zhao, L.J.; Guan, Q.Z. Virtual assembly and load simulation of roadheader cutting head. Adv. Mater. Res. 2011, 156, 754-758. [CrossRef]

21. Li, X.; Lv, Y.; Xu, S.; Zeng, Q.; Huang, B. Optimization design for roadheader cutting head by orthogonal experiment and finite element analysis. Teh. Vjesn. 2016, 23, 707-714. [CrossRef]

22. Zhao, B.; Zong, X.M.; He, B.; Zhang, L.J. Multi Variable Multi Objective Optimization for the Cutting Head of Roadheader. Appl. Mech. Mater. 2014, 635, 358-364. [CrossRef]

23. Li, X.; Liu, Z.; Wang, D.; Li, Y. Parameter Optimization Design of Hard Rock Roadheader Cutting Head Based on PSO. IEEE Proc. Int. Conf. Comput. Appl. Syst. Model. 2012, 677-680. [CrossRef]

24. Wang, Y.; Zou, L.; Zhao, Z.; Bai, X. Ho fuzzy PID control for discrete time-delayed TS fuzzy systems. Neurocomputing 2019, 332, 91-99. [CrossRef]

25. Fan, B.; Yang, Z.X.; Wang, X.B.; Song, L.; Song, S.Z. Model reference adaptive vector control for induction motor without speed sensor. Adv. Mech. Eng. 2017. [CrossRef]

26. Mubarok, M.S.; Liu, T.H.; Tsai, C.Y.; Wei, Z.Y. A Wide-Adjustable Sensorless IPMSM Speed Drive Based on Current Deviation Detection under Space-Vector Modulation. Energies 2020, 13, 4431. [CrossRef]

27. Han, H.; Liu, Y.; Ma, L.; Liu, Z.; Quan, L. Analyze the characteristics of electro-hydraulic servo system's position-pressure master-slave control. Adv. Mech. Eng. 2018. [CrossRef]

28. Yang, Y.; Li, G.; Yuan, A. Performance analysis of a hybrid power cutting system for roadheader. Math. Probl. Eng. 2017. [CrossRef] 